\title{
INTERFUEL: EPAct AFV Compliance Analysis
}

Ron Stewart

February 2020

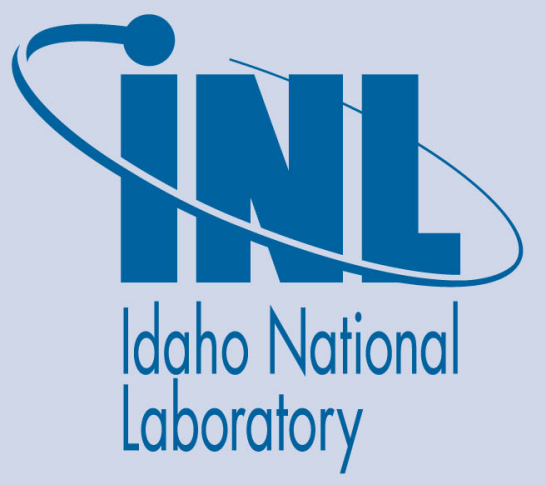

The INL is a U.S. Department of Energy National Laboratory operated by Battelle Energy Alliance 


\title{
INTERFUEL: EPAct AFV Compliance Analysis
}

\author{
Ron Stewart
}

February 2020

Idaho National Laboratory Idaho Falls, Idaho 83415

http://www.inl.gov

Prepared for the U.S. Department of Energy

Office of Energy Efficiency and Renewable Energy Under DOE Idaho Operations Office Contract DE-AC07-05ID14517 


\section{EPAct AFV Acquisition Compliance Analysis}

Ron Stewart

Idaho National Laboratory

INTERFUEL

February 12, 2020

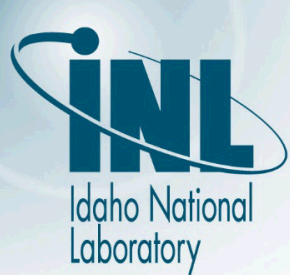




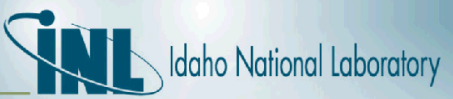

\section{Disclaimers}

All FY 2019 data shown in the following slides is preliminary, subject to change based on agency corrections, and shown here solely to support discussion 


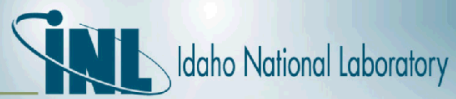

\section{EPAct AFV Compliance Analysis}

Question: What is causing the recent decrease in compliance with the EPAct AFV acquisition requirement? 


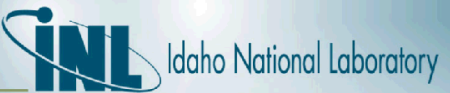

\section{Recent EPAct AFV Acquisition Compliance}

Reported EPAct AFV Acquisition Compliance

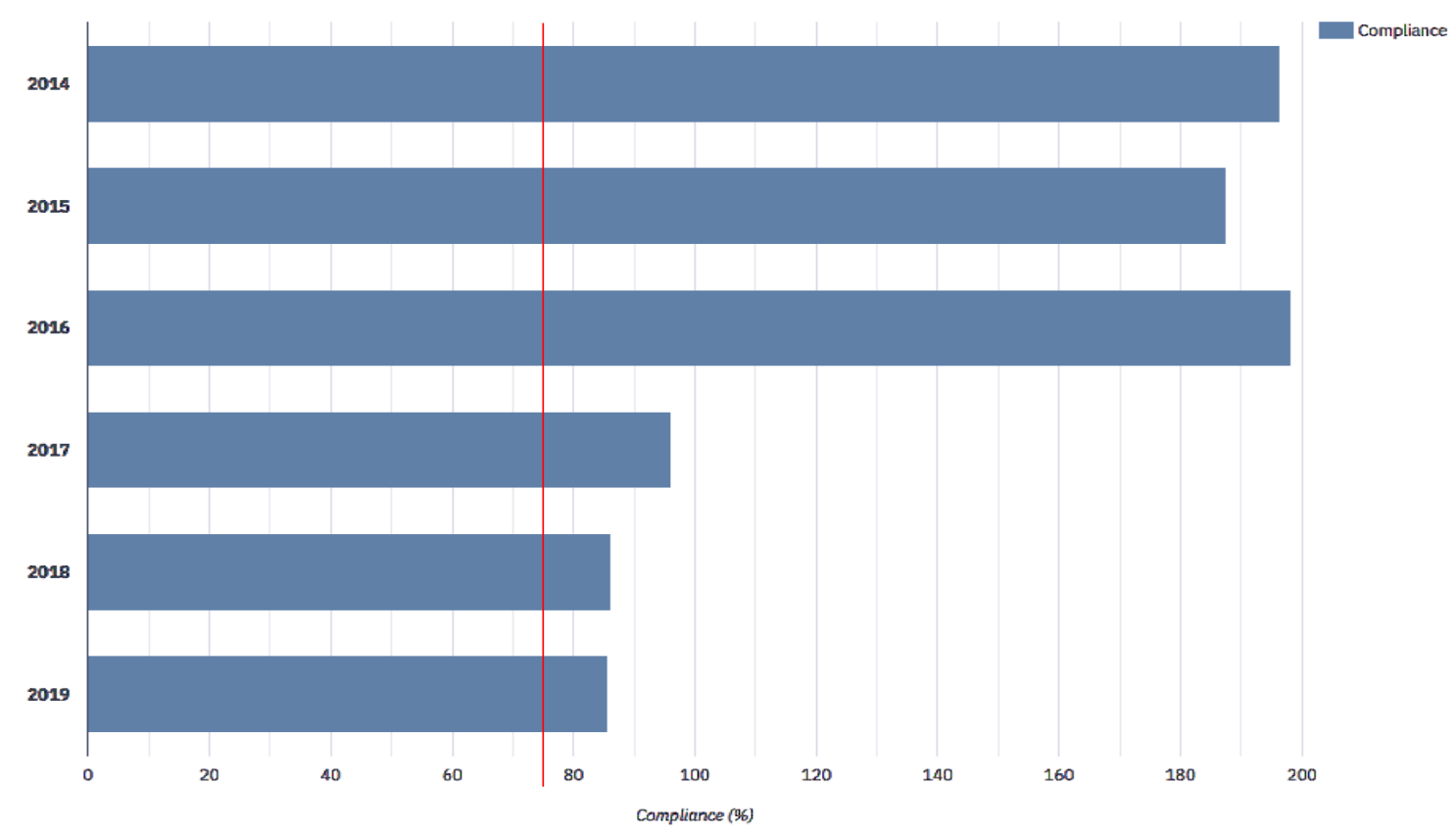




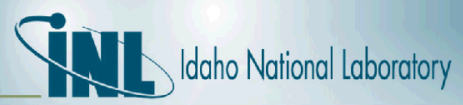

\section{Recent EPAct AFV Acquisition Compliance}

\section{FY 2014 Reported EPAct AFV Acquisition Compliance}

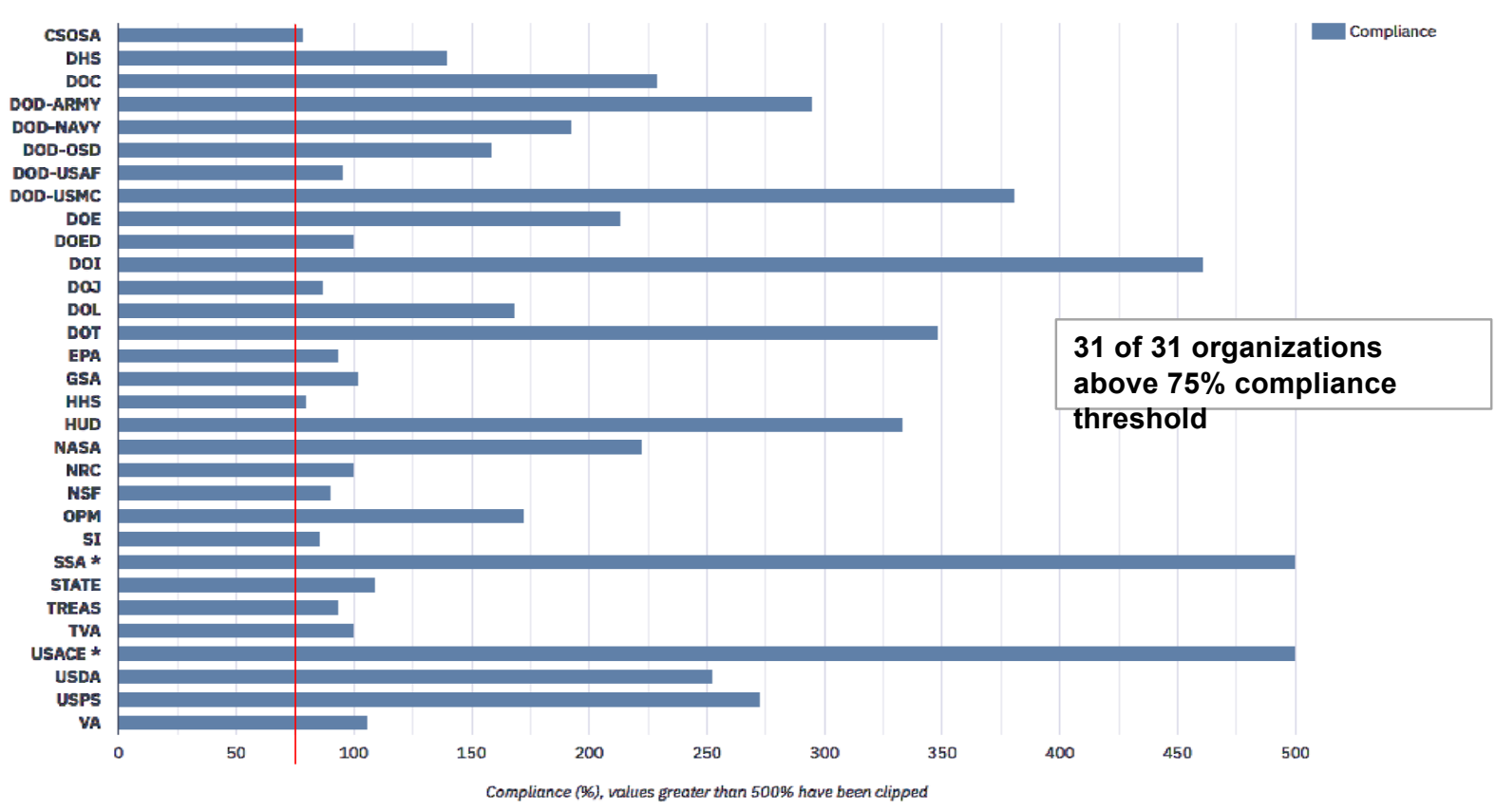

Source: FAST, 2020-01-16. Covered agencies not shown reported no acquisitions and are considered compliant. Any FY 2019 data shown is considered preliminary and subject to 


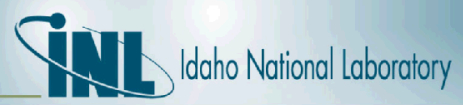

\section{Recent EPAct AFV Acquisition Compliance}

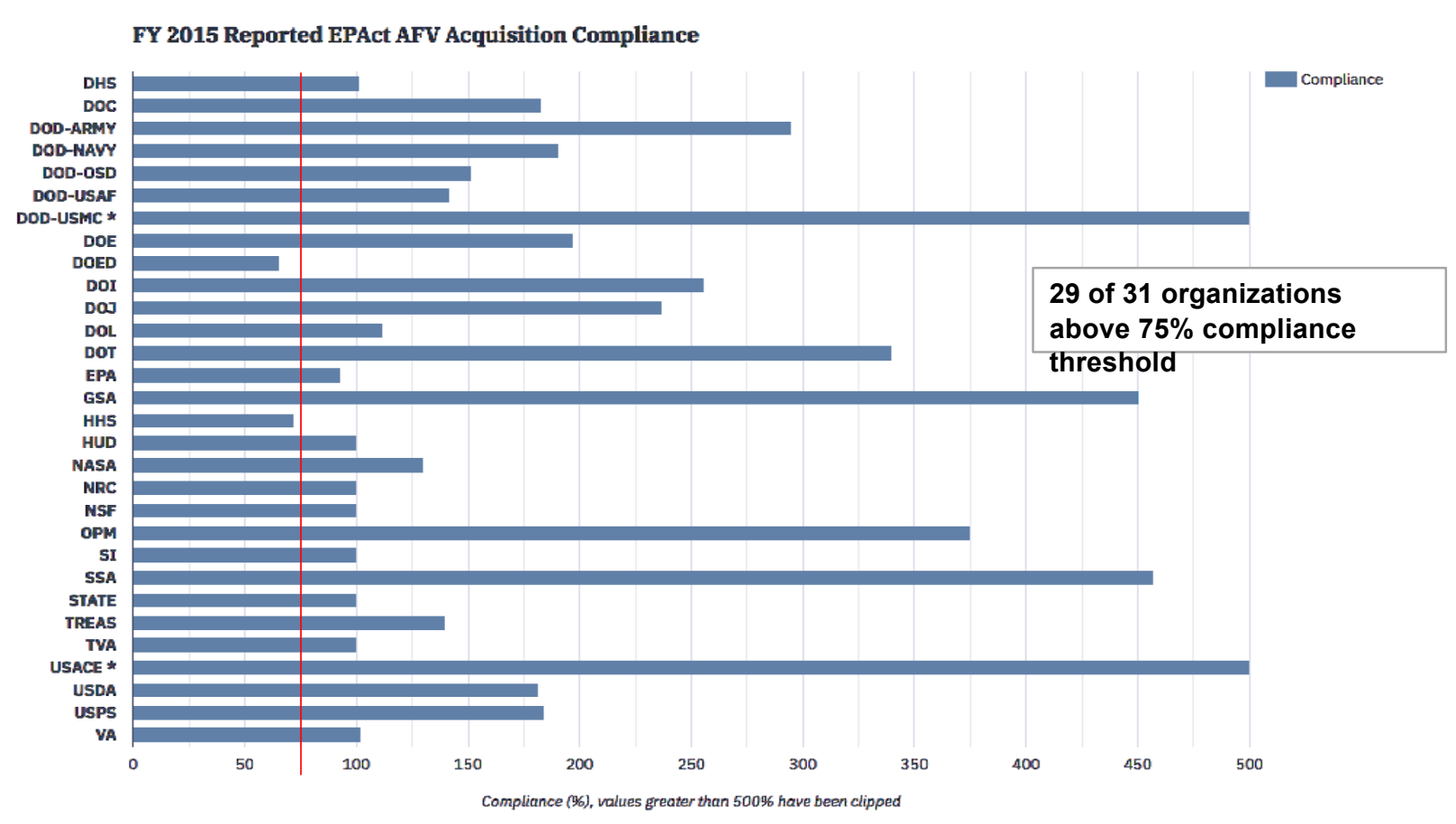

Source: FAST, 2020-01-16. Covered agencies not shown reported no acquisitions and are considered compliant. Any FY 2019 data shown is considered preliminary and subject to 


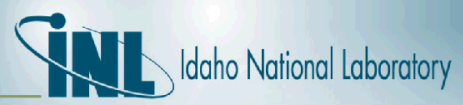

\section{Recent EPAct AFV Acquisition Compliance}

FY 2016 Reported EPAct AFV Acquisition Compliance

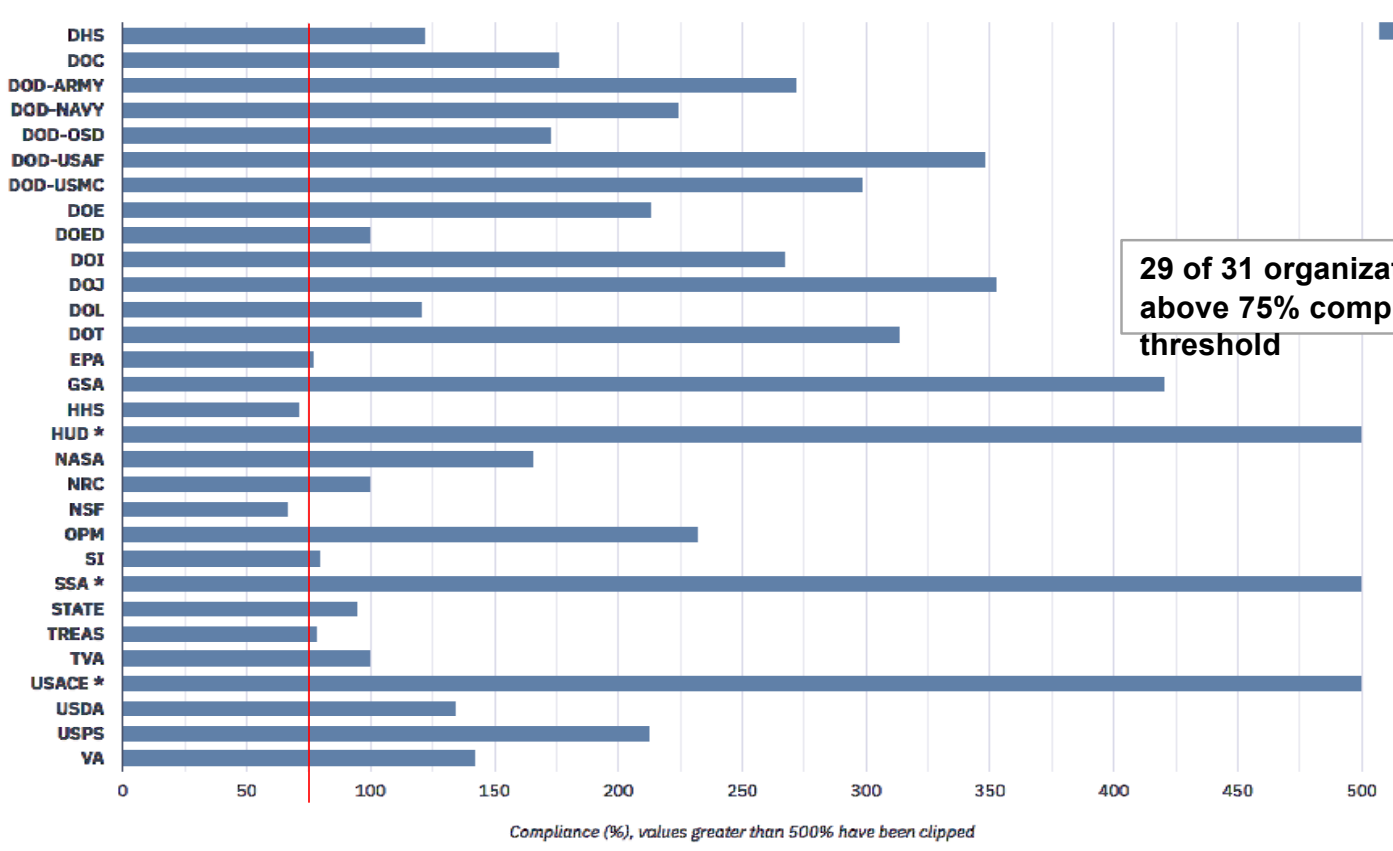




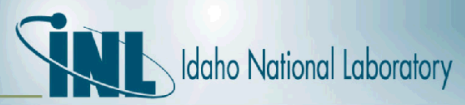

\section{Recent EPAct AFV Acquisition Compliance}

FY 2017 Reported EPAct AFV Acquisition Compliance

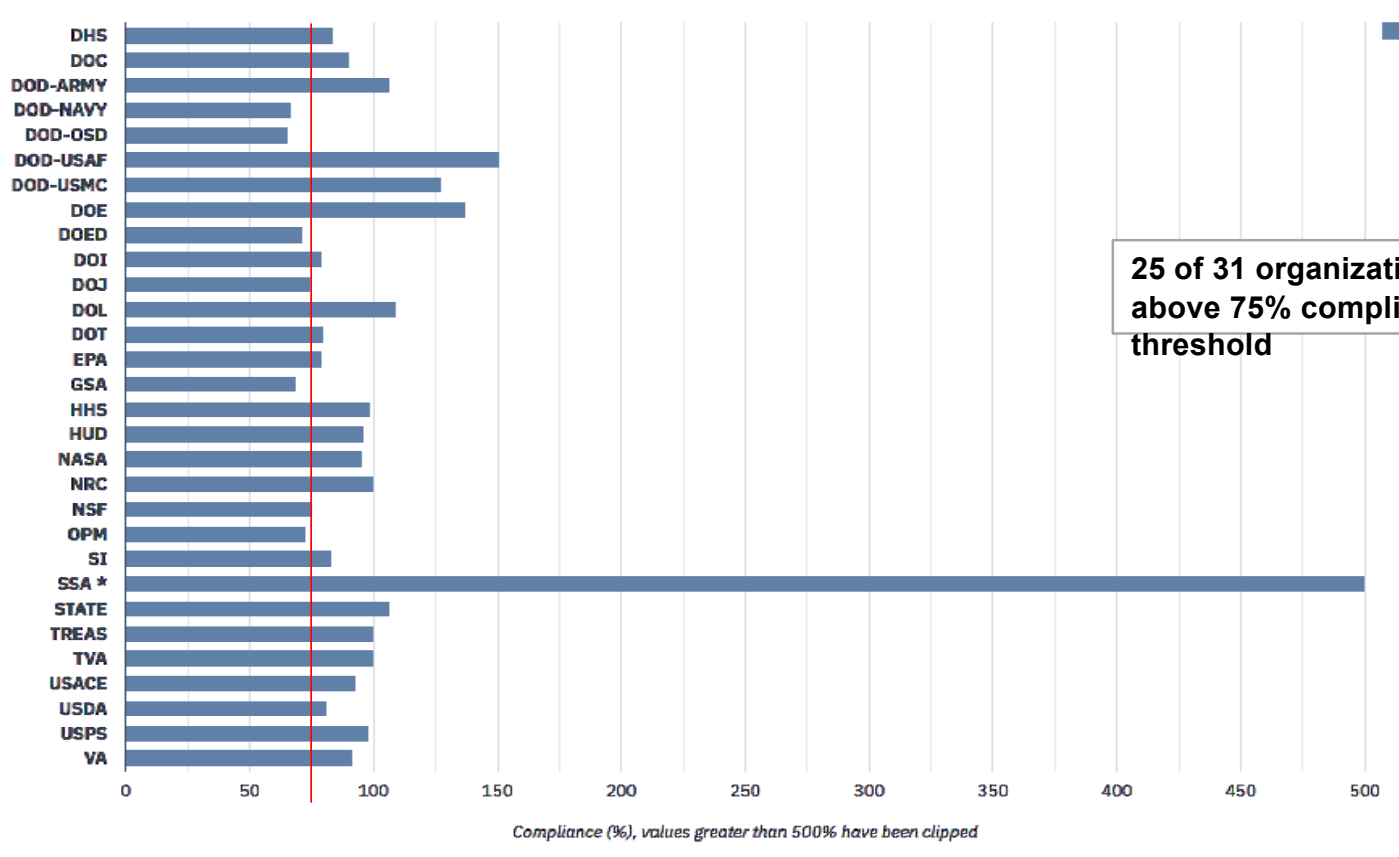

Source: FAST, 2020-01-16. Covered agencies not shown reported no acquisitions and are considered compliant. Any FY 2019 data shown is considered preliminary and subject to 


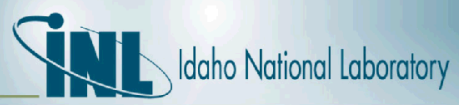

\section{Recent EPAct AFV Acquisition Compliance}

FY 2018 Reported EPAct AFV Acquisition Compliance

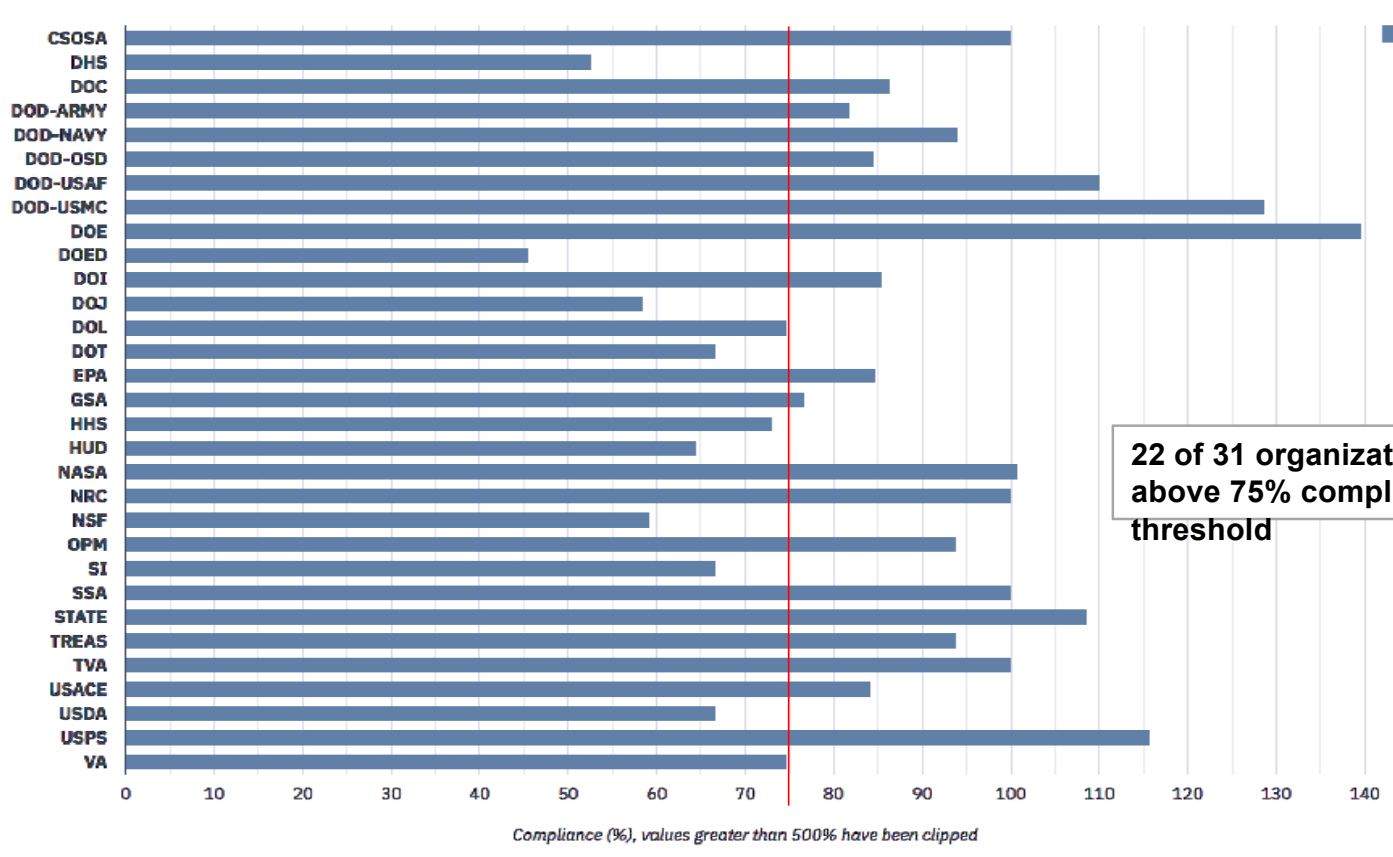

Source: FAST, 2020-01-16. Covered agencies not shown reported no acquisitions and are considered compliant. Any FY 2019 data shown is considered preliminary and subject to 


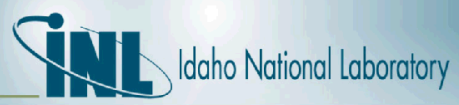

\section{Recent EPAct AFV Acquisition Compliance}

FY 2019 Reported EPAct AFV Acquisition Compliance

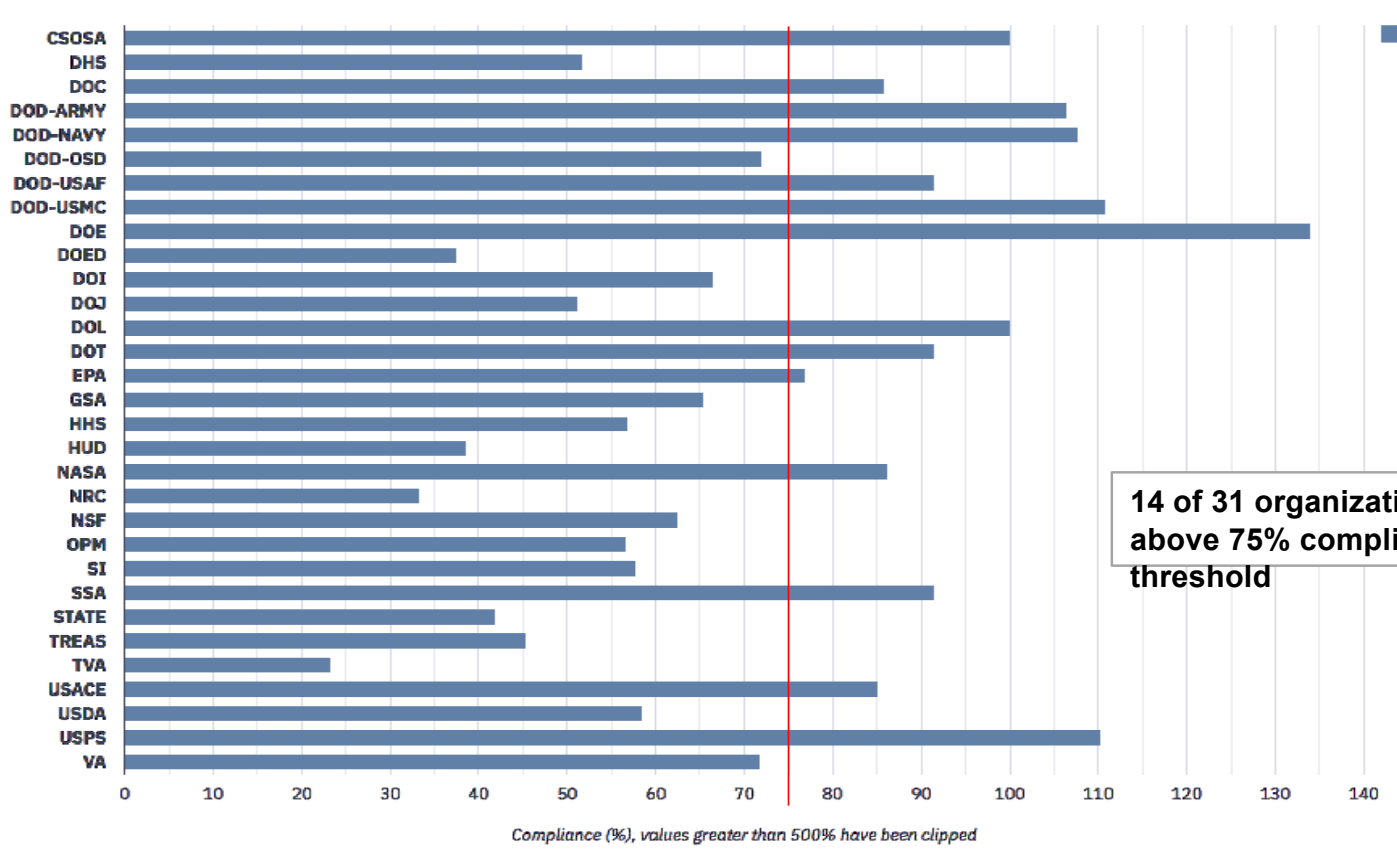

Source: FAST, 2020-01-16. Covered agencies not shown reported no acquisitions and are considered compliant. Any FY 2019 data shown is considered preliminary and subject to 


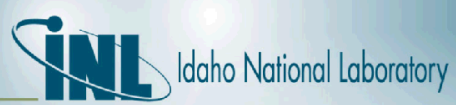

\section{What's behind the drop in compliance?}

- Pre-VLD years' compliance may have been overstated?

- VLD years' compliance significantly understated! 


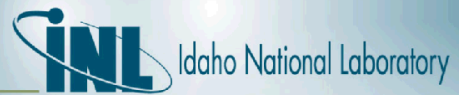

\section{EPAct AFV Acquisition Credits}

EPAct AFV Acquisition Credits: All Covered Agencies

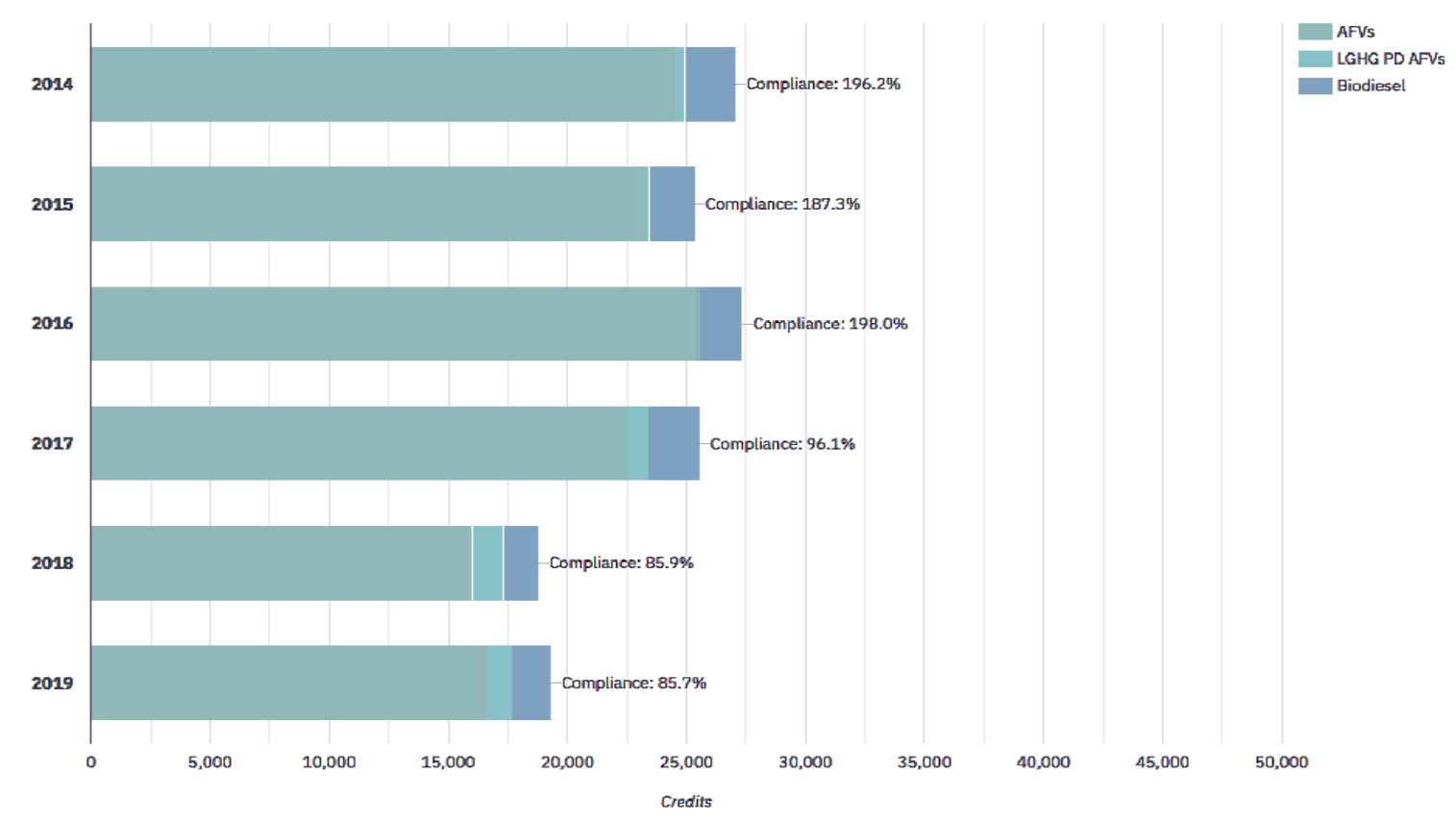




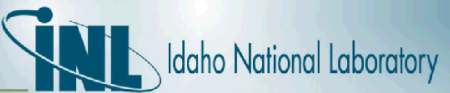

\section{Recent AFV Acquisitions}

AFV Acquisitions: All Covered Agencies

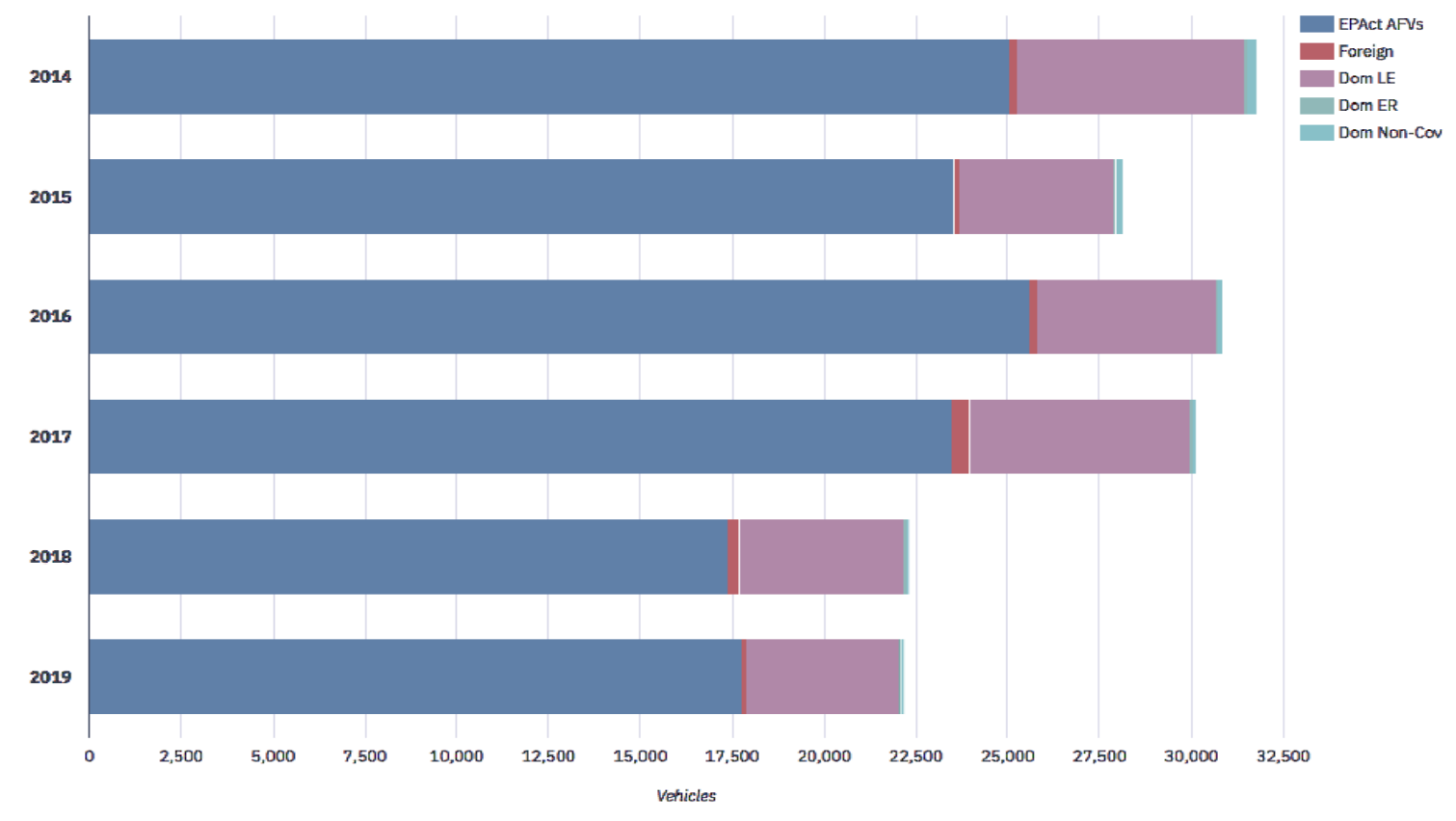




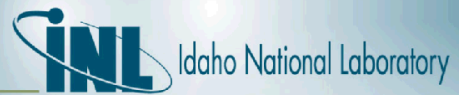

\section{Designation of Light-Duty Acquisitions}

Light-Duty Vehicle Acquisitions: All Covered Agencies

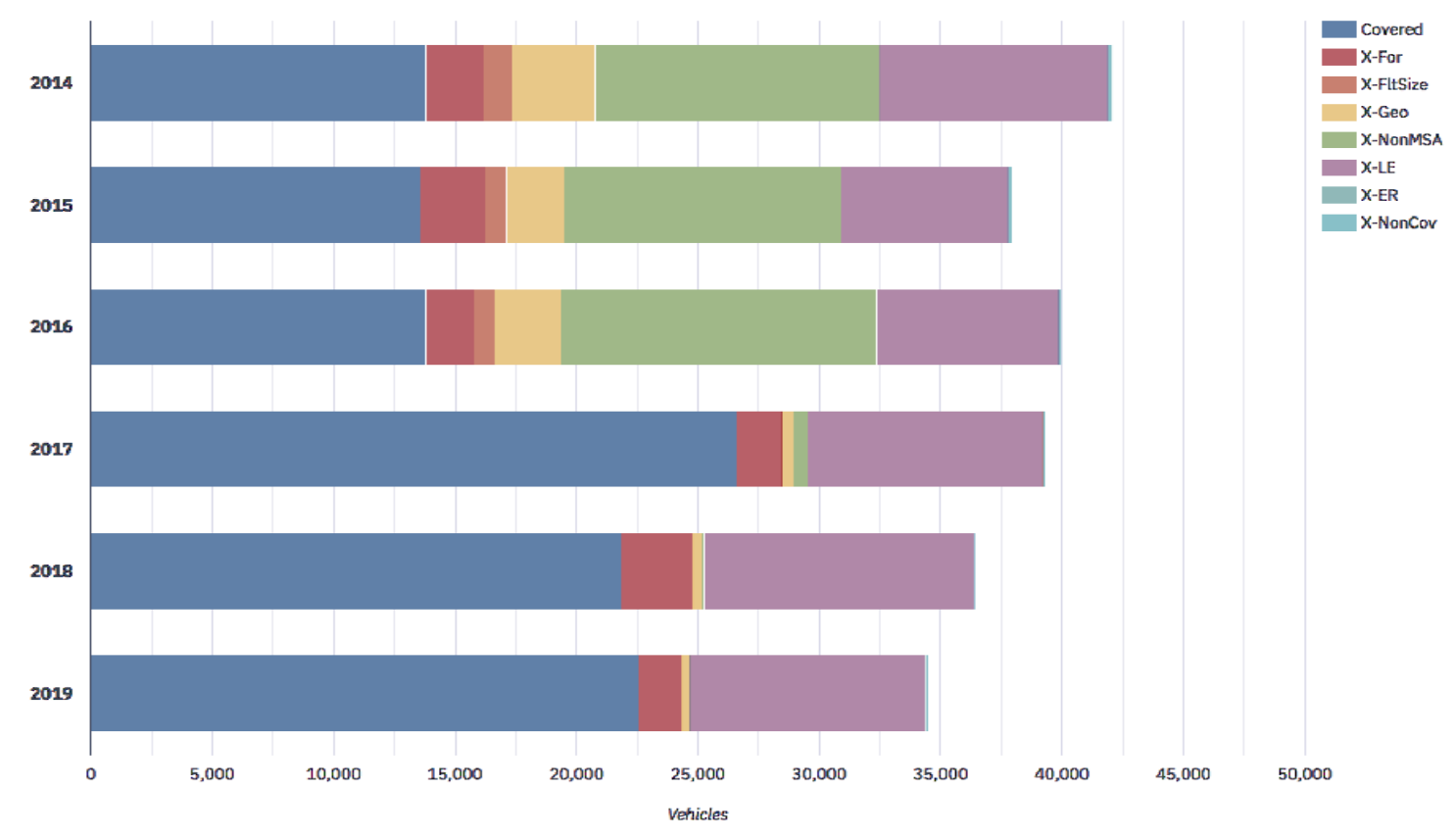




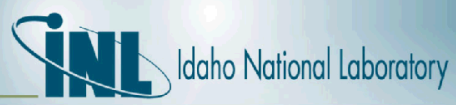

\section{What if we take a different approach?}

- Proposed approach to calculating compliance:

- Use vehicle location information to

- Provide geographic exemptions

- Verify agency-claimed geographic exemptions

- Verify agency-claimed non-MSA operation exemptions

- Yields a more accurate characterization of compliance for FY 2019 and future years

- Note: DOE does not plan to revise pre-2019 compliance figures! 


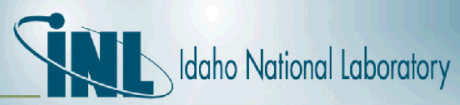

\section{Proposed Approach: Hypothetical Result}
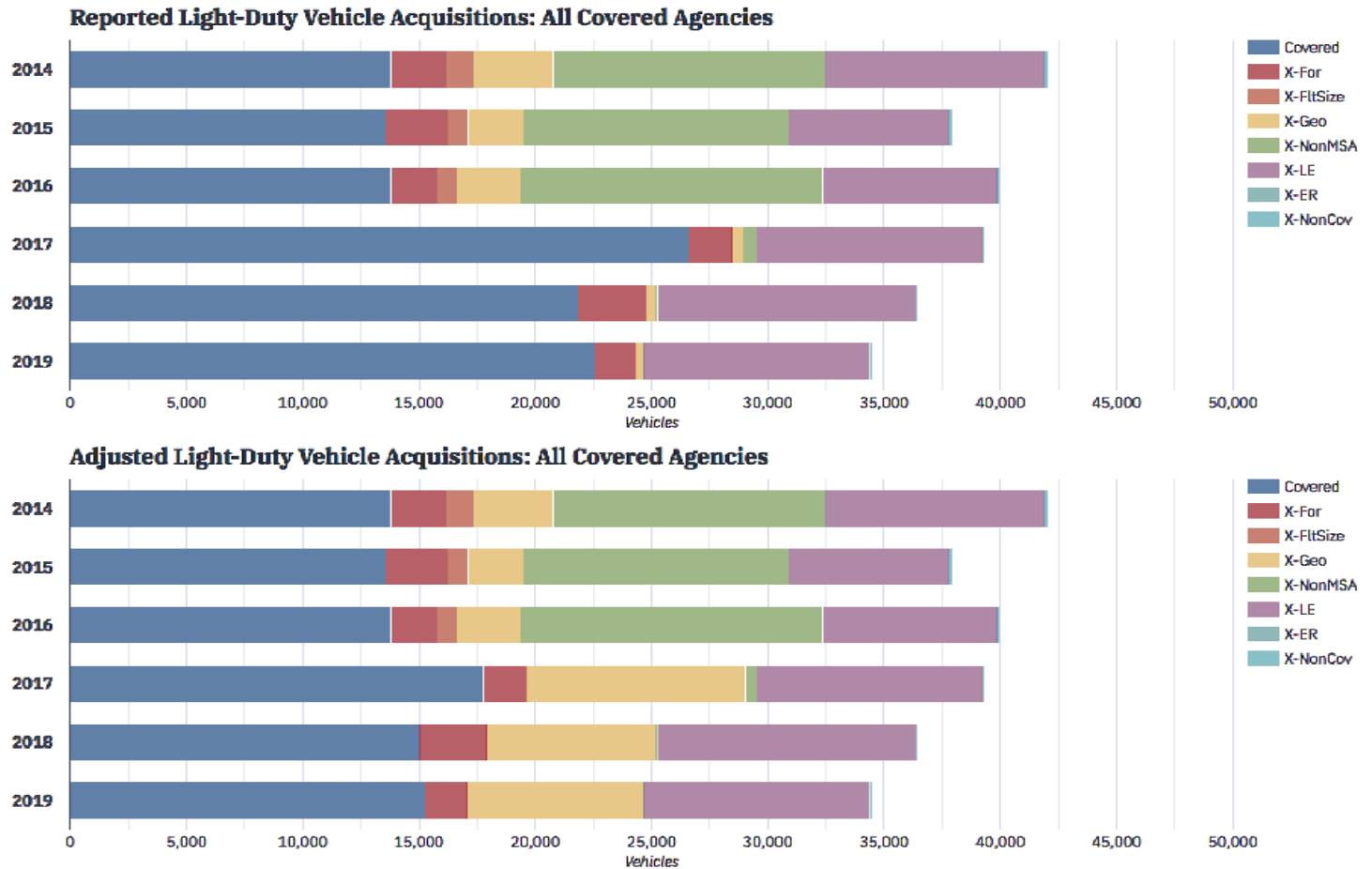

Source: FAST, 2020-01-16. Any FY 2019 data shown is considered preliminary and subject to change. DOE does not plan to revise pre-2019 compliance data; shown here only for illustration. 


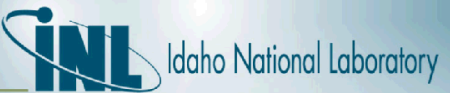

\section{Proposed Approach: Hypothetical Result}

Adjusted EPAct AFV Acquisition Compliance: All Covered Agencies

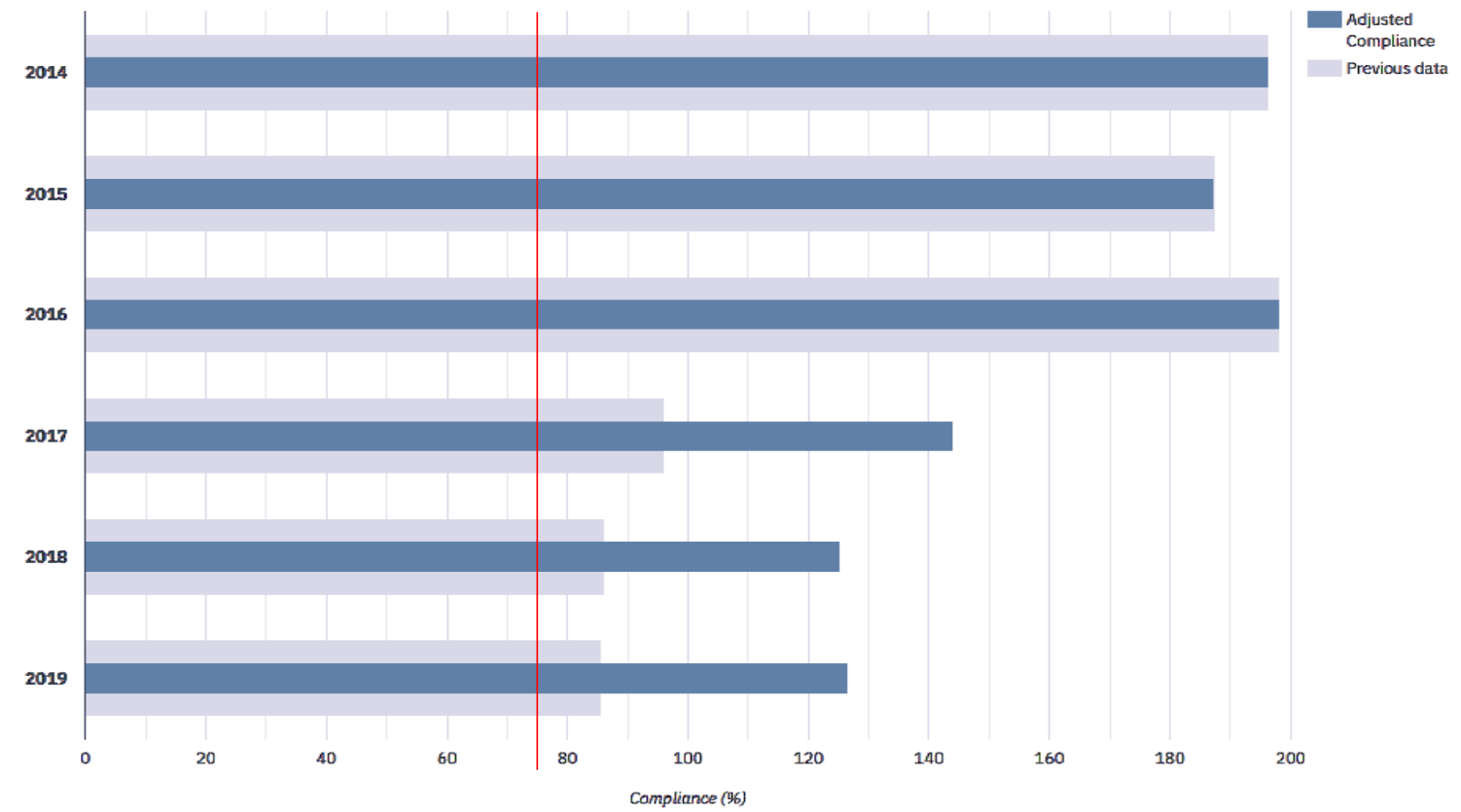




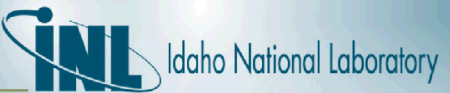

\section{Proposed Approach: Hypothetical Result}

FY 2017 Adjusted EPAct AFV Acquisition Compliance Comparison

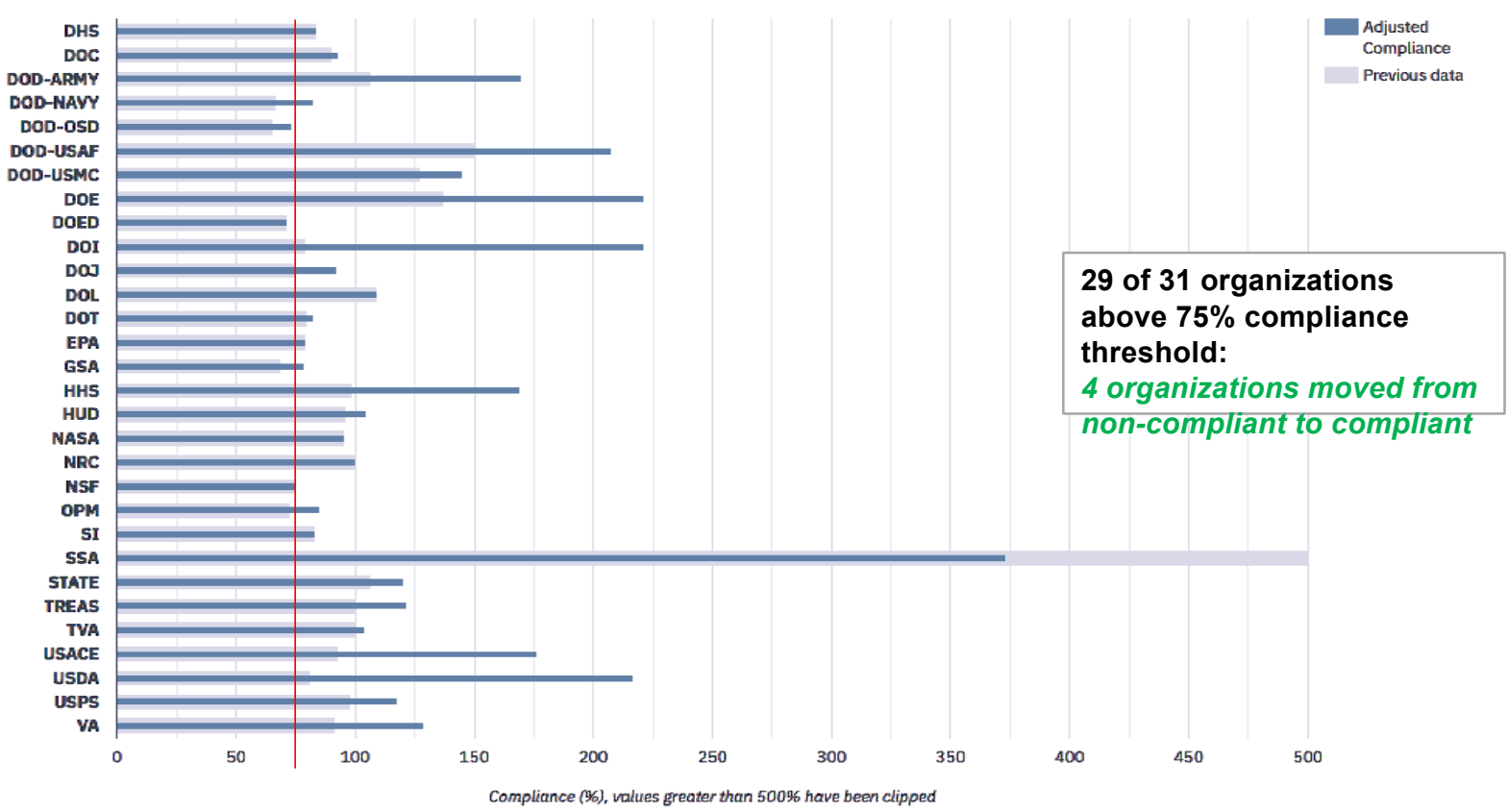




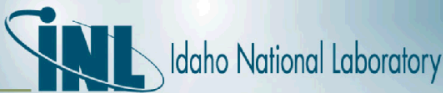

\section{Proposed Approach: Hypothetical Result}

FY 2018 Adjusted EPAct AFV Acquisition Compliance Comparison

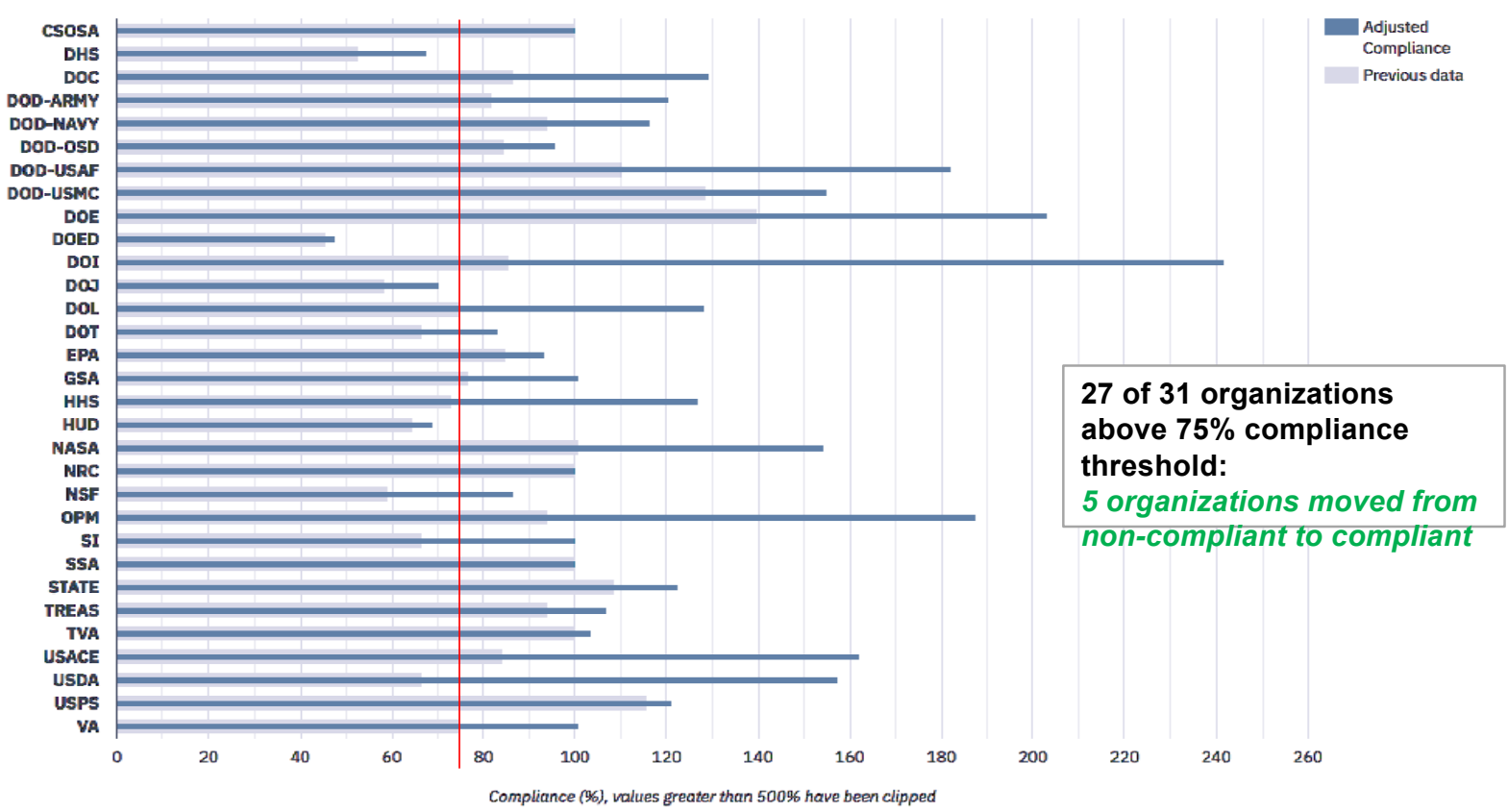

Source: FAST, 2020-01-16. Covered agencies not shown reported no acquisitions and are considered compliant. DOE does not plan to revise pre-2019 compliance data; shown here only for illustration. 


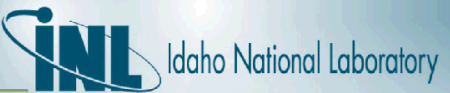

\section{Proposed Approach: Hypothetical Result}

FY 2019 Adjusted EPAct AFV Acquisition Compliance Comparison

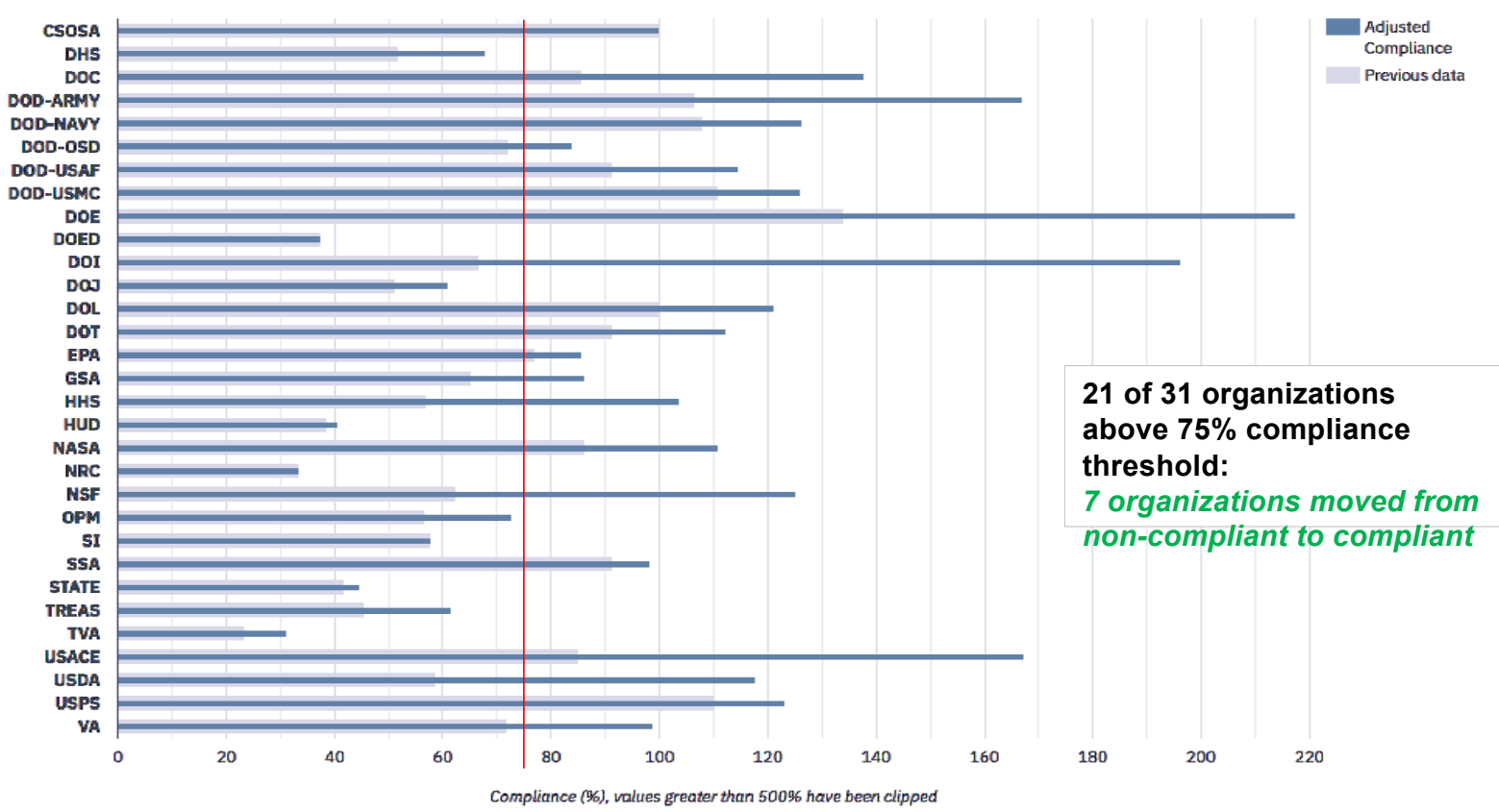

Source: FAST, 2020-01-16. Covered agencies not shown reported no acquisitions and are considered compliant. Any FY 2019 data shown is considered preliminary and subject to 


\section{Idaho National Laboratory}

\section{Discussion}

